\title{
Produção de mudas de aroeira-do-sertão (Myracrodruon urundeuva Allemão) em resíduos orgânicos ${ }^{1}$
}

\author{
Lucas Kennedy Silva Lima ${ }^{2 *}$, Maria da Conceição Freitas Moura ${ }^{2}$, Camila Castro Santos ${ }^{2}$, \\ Karla Pollyanna de Carvalho Nascimento ${ }^{2}$, Alek Sandro Dutra ${ }^{2}$
}

10.1590/0034-737X201764010001

\section{RESUMO}

A aroeira é uma espécie de grande importância devido às diversas utilidades de sua madeira. Entretanto, encontrase na lista de espécies ameaçadas de extinção, em virtude da exploração predatória. Diante da baixa tecnologia empregada na produção de mudas, este trabalho teve por objetivo avaliar o desenvolvimento de mudas de aroeira-do-sertão (Myracrodruon urundeuva Allemão), utilizando diferentes resíduos orgânicos em diferentes concentrações. Foram usados, como substratos, esterco bovino, esterco ovino, húmus de minhoca, resíduo oriundo do processo de torrefação do café e solo. O delineamento experimental utilizado foi o inteiramente casualizado, em esquema fatorial 4 x 4 (resíduos orgânicos x níveis de resíduo), constituído por 16 tratamentos e cinco repetições. Resultados superiores foram alcançados quando utilizado o esterco ovino, para o índice de qualidade de Dickson, massa seca da raiz e massa seca total, com máxima eficiência na concentração de 66\%. Para as demais variáveis, não foi observada variação na comparação com o húmus de minhoca. O resíduo de café provocou efeito alelopático, mesmo nas menores concentrações, não sendo recomendado para formulação de substrato. Na maioria das variáveis, o esterco bovino comportou-se de forma intermediária, com decréscimo das variáveis, decorrentes das concentrações. O esterco de ovino e o húmus de minhoca são recomendados para produção de mudas de aroeira nas concentrações de 66 e $33 \%$, respectivamente.

Palavras-chave: esterco ovino; resíduo de café; substratos; alelopatia; reflorestamento.

\begin{abstract}
Production of aroeiradosertão seedlings (Myracrodruon urundeuva Allemão) in organic waste

The aroeira is a species of great importance due to the diverse uses of its wood. However, it is on the list of endangered species because of predatory exploitation. Given the low technology used in the production of seedlings, this study aimed to evaluate the development of aroeira-do-sertão (Myracrodruon urundeuva Allemão) seedlings using different organic waste in different concentrations. Cattle manure, sheep manure, earthworm humus, waste originating from coffee roasting process, and soil were used as substrates. The experimental design was completely randomized in a factorial $4 \times 4$ (organic waste $\times$ residue levels), consisting of sixteen treatments and five replications. Superior results were achieved, when sheep manure was used, for the Dickison quality index, dry root weight, and total dry weight, with maximum efficiency at a concentration of $66 \%$. For the other variables, no variation was observed compared with the earthworm humus. The coffee residue caused allelopathic effects, even in low concentrations; so, it is not recommended for substrate formulation. In most of the variables, cattle manure had an intermediate behavior, with a decrease of variables depending on the concentrations. Sheep manure and worm humus are recommended for the production of aroeira seedlings at concentrations of 66 and 33\% respectively.
\end{abstract}

Key words: sheep manure; coffee residue; substrates; allelopathy; reforestation.

Submetido em 01/11/2014 e aprovado em 17/10/2016.

${ }^{1}$ Parte da Dissertação de Mestrado do primeiro autor.

${ }^{2}$ Universidade Federal do Ceará, Departamento de Fitotecnia, Fortaleza, Ceará, Brasil. lucas18kennedy@gmail.com; ceicaomoura@hotmail.com; camilacastro30@hotmail.com; karlabelmont@hotmail.com. alekdutra@ufc.br

*Autor para correspondência: lucas18kennedy@gmail.com 


\section{INTRODUÇÃO}

É crescente a preocupação mundial com a manutenção dos ecossistemas naturais e a recuperação de áreas degradadas. Essa demanda, observada nos últimos anos, mostra a necessidade do desenvolvimento de pesquisas que otimizem a produção de mudas a baixo custo, capaz de atender aos objetivos dos plantios (José et al., 2005; Kratka \& Correa, 2015).

A utilização de espécies nativas na recuperação de áreas degradadas tem esbarrado em vários problemas técnicos, destacando-se os relacionados com a falta de conhecimento ecológico, a irregularidade de crescimento e a escolha de métodos silviculturais adequados (Morais et al., 2012).

A ausência de difusão dos conhecimentos existentes faz que muitas espécies florestais valiosas, entre elas a aroeira, sejam subutilizadas (Morais et al., 2012; Scalon $e t$ al., 2012). A aroeira-do-sertão (Myracrodruon urundeuva Allemão - Anacardiaceae) é uma árvore ornamental, medindo de 5 a $20 \mathrm{~m}$ de altura. Sua madeira apresenta grande durabilidade natural e está incluída no grupo das madeiras chamadas imputrescíveis (Lorenzi, 2010). Além disso, a aroeira também é utilizada na composição florística, para recuperação de ambientes perturbados (José et al., 2005; Bertoni \& Dickfeldt, 2007; Scalon et al., 2012).

Entretanto, a exploração vem sendo feita de forma extrativista e desordenada, com forte impacto sobre as populações naturais (Monteiro et al., 2005). Em decorrência dessa exploração predatória, a preservação de populações dentro dos habitats naturais vem sendo comprometida. Como consequência, a aroeira-do-sertão foi inserida na lista oficial de espécies da flora brasileira ameaçadas de extinção, na categoria vulnerável, e também na lista vermelha de espécies ameaçadas de extinção da União Internacional para a Conservação da Natureza e dos Recursos Naturais IUCN (Pacheco et al., 2006).

Um dos problemas encontrados na produção de mudas florestais nativas é o crescimento lento, principalmente daquelas espécies classificadas como tardias ou clímax, como a aroeira. Por essa razão, é de fundamental importância a definição de protocolos que favoreçam a produção de mudas com qualidade, em menor espaço de tempo e em condições acessíveis aos pequenos e médios produtores rurais, em razão de ser esse o público mais interessado nesse insumo (Cunha et al., 2005; Oliveira et al., 2012). Sendo assim, o êxito de plantios florestais, tanto para fins de produção quanto de conservação ou restauração, não está ligado unicamente à espécie utilizada, mas altamente relacionada com a qualidade das mudas produzidas, que depende diretamente do tipo de recipiente, da qualidade das sementes e do substrato utilizado (Caldeira et al., 2012).
O substrato é um dos fatores que exerce influência significativa no desenvolvimento das mudas e vários são os materiais que podem ser usados, na sua composição original ou combinados. Dentre os materiais utilizados como substrato, os resíduos da agroindústria disponíveis na região são opção de baixo custo, além de seu uso auxiliar na redução de sua acumulação no ambiente, pois são considerados potenciais problemas ambientais e representam perdas de matéria-prima e de energia, exigindo investimentos significativos para descarte adequado (Lima et al., 2007; Pelizer et al., 2007; Oliveira et al., 2012; Kratka \& Correa, 2015). A matéria orgânica é um dos componentes fundamentais dos substratos, com a finalidade básica de aumentar a capacidade de retenção de água e de nutrientes para as mudas (Caldeira et al., 2008).

$\mathrm{O}$ uso de um substrato inadequado pode ocasionar irregularidade ou até mesmo nulidade da germinação; logo, o substrato constitui um dos fatores mais complexos da produção de mudas (Araújo \& Sobrinho, 2011). Este trabalho teve por objetivo avaliar o desenvolvimento de mudas de aroeira-do-sertão em virtude da utilização de diferentes resíduos de origem animal e vegetal, testados em diferentes percentagens.

\section{MATERIAL E MÉTODOS}

O experimento foi instalado em Casa de Vegetação do Departamento de Fitotecnia, do Centro de Ciências Agrárias da Universidade Federal do Ceará, Campus do Pici. As sementes foram coletadas em dez matrizes, vigorosas e livres do ataque de pragas e doenças, no ano de 2013, na Fazenda Experimental Vale do Curu/FEVC, em Pentecoste, CE. O estudo foi constituído por 16 tratamentos, composto por solo, esterco bovino (EB), esterco ovino (EO), húmus de minhoca (HM) e resíduo de café (RC) (Tabela 1).

O solo utilizado na formulação dos substratos foi coletado da camada de 0-20 cm do perfil, em área experimental do Departamento de Fitotecnia; os estercos (bovino e ovino) foram obtidos junto ao setor de produção animal da Universidade Federal do Ceará, Campus do Pici; o resíduo do café foi obtido junto à empresa Três Corações localizada no município de Eusébio, CE; o húmus de minhoca foi obtido no comércio especializado de produtos agropecuários. Todos os constituintes do substrato foram submetidos à análise química, cujos resultados estão presentes na Tabela 2.

A uma profundidade de $3,0 \mathrm{~cm}$, foram semeadas três sementes em cada recipiente, (saco de polietileno preto, com furos na base e dimensões de $28 \mathrm{~cm}$ x $10 \mathrm{~cm}$, fechado). Após 15 dias realizou-se o desbaste, permanecendo apenas a plântula mais vigorosa por recipiente. A irrigação foi realizada diariamente, no final da tarde, com rega- 
dor. As médias da umidade relativa do ar e da temperatura no interior da casa de vegetação, obtidas a partir do Datalogger HT-500, durante a pesquisa, podem ser observadas na Figura 1. Durante a condução do estudo, as temperaturas máxima e mínima encontradas foram de 42,7 e $22,4^{\circ} \mathrm{C}$, respectivamente.

As variáveis analisadas aos 55 dias após a semeadura foram: altura da planta (Al), medida da distância entre o colo da planta e a gema apical com uma régua milimétrica; diâmetro do caule na região do colo da planta (DC), aferido com paquímetro; comprimento da raiz $(\mathrm{CR})$, após a separação da parte aérea e raiz, determinado com régua milimétrica até o seu ápice.

A matéria seca da parte aérea (MSPA) (folhas e caule) e a massa seca da raiz (MSR), foram aferidas em balança de precisão $(0,000 \mathrm{~g})$, após desidratação em estufa, regulada a $65^{\circ} \mathrm{C}$, por $72 \mathrm{~h}$; a área foliar (AF) foi determinada com medidor portátil de área foliar LI-3050C; os teores de clorofilas A e B foram obtidos com o equipamento Clorofilog CFL1030 e o índice de qualidade de Dickson (IQD) foi obtido pela fórmula de Dickson et al. (1960):

$\mathrm{IQD}=\frac{\operatorname{MST}_{(\mathrm{g})}}{\mathrm{Al}_{(\mathrm{cm})} / \mathrm{DC}_{(\mathrm{mm})}+\operatorname{MSPA}_{(\mathrm{g})} / \mathrm{MSR}_{(\mathrm{g})}}$

O delineamento experimental utilizado foi o inteiramente ao acaso, em esquema fatorial 4 x 4 (resíduo orgânico $\mathrm{x}$ proporções), com 16 tratamentos (Tabela 2) e cinco repetições, sendo cada repetição constituída por cinco plantas. Os dados foram submetidos à análise de variância. A comparação de médias entre os resíduos foi realizada pelo teste de Tukey, a 5\% de probabilidade. Para as propor- ções volumétricas, foi realizado o teste de regressão. Além disso, foi realizada análise de normalidade e homogeneidade e todas as variáveis apresentavam-se normais e homogêneas, quando analisadas na ausência do tratamento resíduo do café, cujo uso impossibilitou a germinação em função do acréscimo da proporção volumétrica, impedindo assim que os dados se comportassem de forma normal. Portanto, foi realizada a análise estatística na ausência do tratamento (resíduo do café) e exposição das médias obtidas.

\section{RESULTADOS E DISCUSSÃO}

A interação entre os resíduos orgânicos e suas percentagens de uso não foi significativa para nenhuma das variáveis analisadas neste trabalho (Tabela 3), exceto para massa seca da parte aérea (MSPA), indicando a independência entre fatores, ou seja, os resíduos orgânicos independem da percentagem utilizada na formulação do substrato e a percentagem independe do tipo de resíduo. Na prática, não é possível escolher nenhum dos resíduos analisados neste trabalho, a partir da percentagem utilizada, em virtude da ausência de interação.

As percentagens de resíduo orgânico na formulação do substrato apresentaram variação significativa para maioria das variáveis, não sendo constatada variação para área foliar e teores de clorofilas A e B, associada à, zona adequada de fornecimento de nutrientes para essas variáveis, cujo acréscimo ou diminuição na percentagem não influenciou estatisticamente, ou à independência da variável aos acréscimos de resíduo na formulação do substrato (Tabela 3).

Tabela 1: Componentes dos substratos (tratamentos) utilizados no estudo para produção de mudas de aroeira-do-sertão (Myracrodruon urundeuva)

\begin{tabular}{|c|c|c|c|c|c|}
\hline \multirow[b]{2}{*}{ Tratamentos } & \multicolumn{5}{|c|}{ Componentes } \\
\hline & Solo & $\begin{array}{c}\text { Esterco } \\
\text { Bovino }(\mathbf{E B})\end{array}$ & $\begin{array}{c}\text { Esterco } \\
\text { Ovino (EO) }\end{array}$ & $\begin{array}{c}\text { Húmus } \\
\text { de minhoca }(H M)\end{array}$ & $\begin{array}{c}\text { Resíduo de café } \\
\text { (RC) }\end{array}$ \\
\hline$\overline{\mathrm{T} 1}$ & 77 & 33 & - & - & - \\
\hline $\mathrm{T} 2$ & 50 & 50 & - & - & - \\
\hline $\mathrm{T} 3$ & 33 & 66 & - & - & - \\
\hline $\mathrm{T} 4$ & 25 & 75 & - & - & - \\
\hline T5 & 77 & - & 33 & - & - \\
\hline T6 & 50 & - & 50 & - & - \\
\hline $\mathrm{T} 7$ & 33 & - & 66 & - & - \\
\hline $\mathrm{T} 8$ & 25 & - & 75 & - & - \\
\hline T9 & 77 & - & - & 33 & - \\
\hline $\mathrm{T} 10$ & 50 & - & - & 50 & - \\
\hline $\mathrm{T} 11$ & 33 & - & - & 66 & - \\
\hline $\mathrm{T} 12$ & 25 & - & - & 75 & - \\
\hline $\mathrm{T} 13$ & 77 & - & - & - & 33 \\
\hline $\mathrm{T} 14$ & 50 & - & - & - & 50 \\
\hline $\mathrm{T} 15$ & 33 & - & - & - & 66 \\
\hline $\mathrm{T} 16$ & 25 & - & - & - & 75 \\
\hline
\end{tabular}


A germinação de sementes de aroeira foi inibida, chegando ao ponto da inibição completa, nos tratamentos com resíduo de torrefação do café, (T13, T14, T15, T16), , quando utilizadas as maiores proporções, o que se atribui ao efeito alelopático desse resíduo, razão por que essas proporções não foram analisadas. De acordo com Lima et al. (2007), a cafeína e os fenóis encontrados no grão do café são metabólitos secundários que propiciam efeitos alelopáticos em diversas es- pécies vegetais. Sementes de cafeeiro possuem diversos alcaloides, como cafeína, theobromina, theofilina e paraxantina, além dos ácidos clorogênico, ferúlico, cumárico, cafeico e vanílico. Conforme Rosa et al. (2006), a cafeína é o alcaloide encontrado em maior quantidade em diversos tecidos e órgãos do cafeeiro, principalmente nas sementes, flores e folhas. Diversos estudos indicam que ela age como agente alelopático, anti-herbívoro.

Tabela 2: Características física e química do solo utilizado na formulação dos substratos, atributos químicos do resíduo do café, húmus de minhoca, esterco ovino e bovino

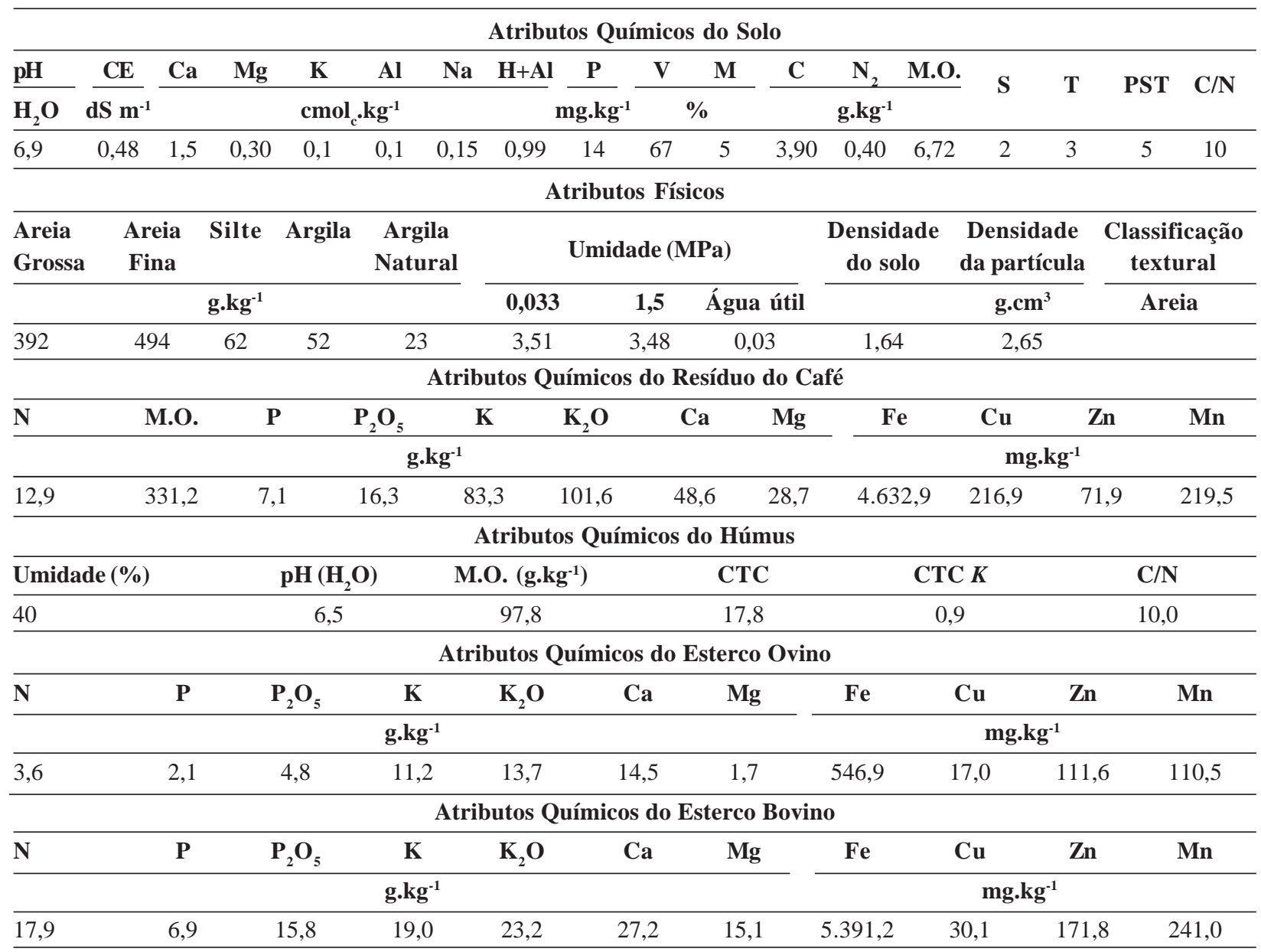

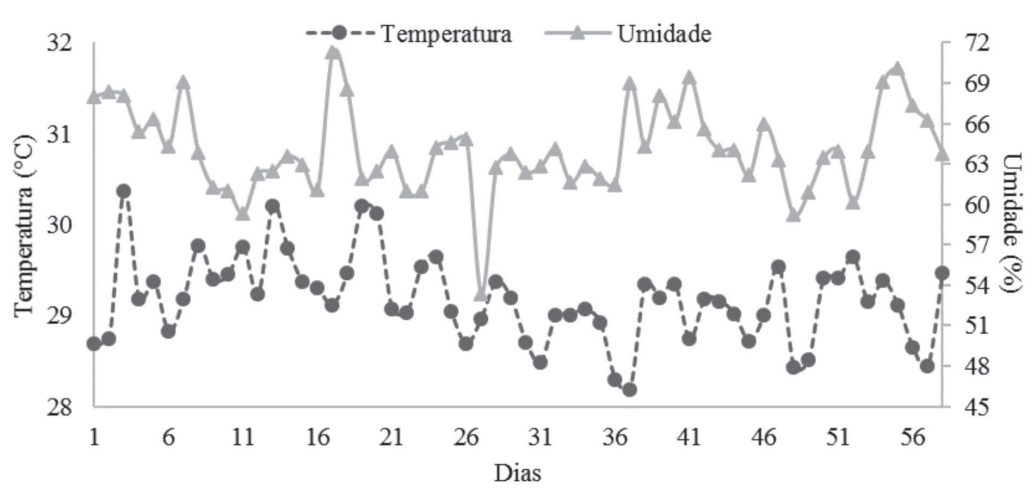

Figura 1: Temperatura e umidade médias internas na casa de vegetação, durante a condução do experimento. 
Tabela 3: Resumo da análise de variância para variáveis respostas das mudas de aroeira-do-sertão (Myracrodruon urundeuva) em função de diferentes substratos e percentagens na mistura com solo mineral

\begin{tabular}{|c|c|c|c|c|c|c|c|c|c|c|}
\hline FV & gl & Al & DC & CR & MSPA & MSR & $\mathbf{A F}$ & Clor $a$ & Clor $b$ & IQD \\
\hline Adubos & 2 & $677,8 * *$ & $5,87 * *$ & $367,8^{*}$ & $17,69 * *$ & $1,94 * *$ & $306392,3 * *$ & $52,37 * *$ & $4,61 * *$ & $0,168 * *$ \\
\hline Doses & 3 & $270,2 * *$ & $2,05^{*}$ & $2,09 *$ & $6,42 * *$ & $3,05 * *$ & $75548,63^{\text {ns }}$ & $12,38^{\mathrm{ns}}$ & $1,45^{\mathrm{ns}}$ & $0,124 * *$ \\
\hline $\mathrm{AxD}$ & 6 & $187,6^{\mathrm{ns}}$ & $1,52^{\mathrm{ns}}$ & $132,4^{\mathrm{ns}}$ & $4,34 *$ & $1,91^{\mathrm{ns}}$ & $48558,56^{\mathrm{ns}}$ & $13,42^{\mathrm{ns}}$ & $0,91^{\mathrm{ns}}$ & $0,03^{\mathrm{ns}}$ \\
\hline Erro & 33 & 90,17 & 0,785 & 105,7 & 1,826 & 0,297 & 44071,37 & 7,086 & 0,578 & 0,0183 \\
\hline Média & & 33,98 & 3,28 & 27,64 & 2,74 & 1,02 & 435,25 & 28,40 & 5,20 & 0,2803 \\
\hline C.V. $(\%)$ & & 27,94 & 26,99 & 37,21 & 49,23 & 53,42 & 48,23 & 9,37 & 14,63 & 48,38 \\
\hline \multicolumn{11}{|c|}{ Regressão Bovino } \\
\hline Lin. & 1 & $548,3^{*}$ & $6,86 * *$ & $1185,4 * *$ & $0,79^{\text {ns }}$ & $1,86^{*}$ & $72684,7^{\mathrm{ns}}$ & $37,34 *$ & $2,81^{*}$ & $0,053^{\text {ns }}$ \\
\hline Quadr. & 1 & $0,23^{\mathrm{ns}}$ & $0,11^{\mathrm{ns}}$ & $22,26^{\mathrm{ns}}$ & $5,27 *$ & $0,006^{\mathrm{ns}}$ & $9075,93^{\mathrm{ns}}$ & $0,63^{\mathrm{ns}}$ & $0,0001 *$ & $0,025^{\mathrm{ns}}$ \\
\hline Cúb. & 1 & $390,02^{\mathrm{ns}}$ & $0,26^{\mathrm{ns}}$ & $14,41^{\mathrm{ns}}$ & $11,01 * *$ & $2,35^{*}$ & $64845,09^{\text {ns }}$ & $13,69^{\text {ns }}$ & $0,272^{\text {ns }}$ & $6,33^{*}$ \\
\hline Erro & 16 & 91,67 & 0,64 & 88,13 & 1,05 & 0,34 & 29400,3 & 6,93 & 0,367 & 0,015 \\
\hline \multicolumn{11}{|c|}{ Regressão Ovino } \\
\hline Lin. & 1 & $19,80^{\mathrm{ns}}$ & $0,33^{\mathrm{ns}}$ & $5,76^{\mathrm{ns}}$ & $0,12^{\mathrm{ns}}$ & $1,22 *$ & $6448,7^{\mathrm{ns}}$ & $9,81^{\mathrm{ns}}$ & $0,12^{\mathrm{ns}}$ & $0,015^{\mathrm{ns}}$ \\
\hline Quadr. & 1 & $46,51^{\mathrm{ns}}$ & $0,04^{\mathrm{ns}}$ & $204,8^{\mathrm{ns}}$ & $0,73^{\text {ns }}$ & $4,49 * *$ & $15051,4^{\mathrm{ns}}$ & $0,28^{\mathrm{ns}}$ & $0,032^{\mathrm{ns}}$ & $0,146^{* *}$ \\
\hline Cúb. & 1 & $832,32 *$ & $6,12 *$ & $0,04 *$ & $23,44 * *$ & $1,25^{*}$ & $236460,4^{\mathrm{ns}}$ & $12,23^{\mathrm{ns}}$ & $1,83^{\mathrm{ns}}$ & $0,139 * *$ \\
\hline Erro & 16 & 112,06 & 0,91 & 78,60 & 2,21 & 0,21 & 56949,71 & 5,59 & 0,609 & 0,014 \\
\hline \multicolumn{11}{|c|}{ Regressão Húmus } \\
\hline Lin. & 1 & $7,84^{\mathrm{ns}}$ & $1,46^{\mathrm{ns}}$ & $11,22^{\mathrm{ns}}$ & $1,05^{\mathrm{ns}}$ & $0,46^{\mathrm{ns}}$ & $50250,8^{\mathrm{ns}}$ & $1,01^{\mathrm{ns}}$ & $1,03^{\mathrm{ns}}$ & $0,025^{\text {ns }}$ \\
\hline Quadr. & 1 & $72,20^{\text {ns }}$ & $0,07^{\mathrm{ns}}$ & $0,31^{\mathrm{ns}}$ & $2,39^{\mathrm{ns}}$ & $0,79^{\text {ns }}$ & $56946,8^{\mathrm{ns}}$ & $42,63^{*}$ & $3,72 *$ & $0,072^{\mathrm{ns}}$ \\
\hline Cúb. & 1 & $19,36^{\mathrm{ns}}$ & $0,03^{\mathrm{ns}}$ & $0,11^{\mathrm{ns}}$ & $0,51^{\mathrm{ns}}$ & $0,12^{\mathrm{ns}}$ & $6233,26^{\mathrm{ns}}$ & $0,096^{\mathrm{ns}}$ & $0,01^{\mathrm{ns}}$ & $0,0092^{\mathrm{ns}}$ \\
\hline Erro & 16 & 66,77 & 0,80 & 150,63 & 2,21 & 0,33 & 45864,03 & 8,727 & 0,76 & 0,025 \\
\hline
\end{tabular}

ns, ** e *: não significativo e significativo a 1 e $5 \%$, respectivamente, pelo teste de $\mathrm{F}$. altura da planta (Al), diâmetro do caule (DC), comprimento da raiz (CR), massa seca da parte aérea (MSPA), massa seca da raiz (MSR), área foliar (AF), teor de clorofila $a$ e $b$ e índice de qualidade de Dickson (IQD). 
Resultados superiores para os componentes morfofisiológicos altura de planta e teores de clorofilas A e B foram observados, quando utilizado o esterco de ovino e o húmus de minhoca como constituintes do substrato (Tabela 4), e estão associados ao equilíbrio nutricional proporcionado pelo esterco ovino e pelo húmus de minhoca. De acordo com Faustino et al. (2005), os incrementos biométricos de mudas de espécies florestais estão relacionados em parte com os acréscimos de matéria orgânica (MO) no substrato. Diferentes estudos têm mostrado que substratos ricos em MO propiciam maior crescimento das mudas, com boa formação do sistema radicular e melhor balanço nutricional. Nessa fase de crescimento, são requeridas elevadas concentrações de $\mathrm{N}$ e $\mathrm{P}$ nos substratos (Pelissari, 2009). Mudas maiores em altura, comprimento da raiz e diâmetro facilitam as operações de plantio, diminuindo principalmente as perdas por danos físicos no transporte e no manuseio no campo (Tsukamoto Filho et al., 2013; Cruz et al. 2006; Souza et al., 2006).

Médias inferiores, quando utilizado o esterco de bovino, foram observadas para altura e teor de clorofila A e B. $O$ efeito desse resíduo orgânico não divergiu daquele do húmus de minhoca quanto ao diâmetro de caule, ao comprimento de raiz, ao índice de qualidade de Dickson, às massas secas da raiz e total e à área foliar (Tabela 4). Desse modo, pode-se observar superioridade do esterco ovino sobre o bovino, que, por sua vez, mostrou semelhança com o húmus de minhoca. O comportamento do esterco bovino inferior ao de ovino pode estar associado às elevadas concentrações de macros e de micronutrientes do esterco bovino, menores no de ovino (Tabela 2). Caldeira et al. (2012), utilizando diferentes substrato na produção de mudas de Toona ciliata, entre eles o esterco bovino, obtiveram concentração de macro e de micronutrientes divergentes dos apresentados aqui, com 4,6; 1,6; 4,5; 12,7;

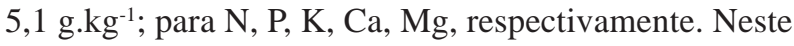
trabalho, foram obtidos teores bem mais elevados, de 17,9; 6,$9 ; 19,0 ; 27,2 ; 15,1$ para N, P, K, Ca, Mg respectivamente. O tempo de curtimento, a ração, a idade do animal e o sistema de criação interferem de forma significativa na constituição química dos estercos, sendo essa a provável razão para o baixo crescimento das mudas, quando utilizado o esterco de bovino. Além disso, durante a formulação dos substratos, fatores como a origem do material, as formas de obtenção, a ausência ou as baixas concentrações de elementos tóxicos devem ser considerados (Kratz et al., 2013). Dessa forma, a caracterização das propriedades químicas, físicas, físico-químicas e biológica desses materiais é de importância fundamental.

Quando utilizado o esterco bovino, as mudas de aroeira apresentaram menores concentrações de clorofilas A e B, mostrando que essas variáveis, não são somente determinadas pela intensidade luminosa e pelo nível de sombreamento. A elevada concentração de determinado nutriente ou associação antagônica entre eles promove distúrbios de ordem fisiológicas no vegetal, sendo o provável motivo para os resultados observados. Conforme Taiz \& Zeiger (2013), à medida que a concentração de nutrientes aumenta além da adequada, o crescimento diminui em decorrência da toxidade.

O índice de qualidade de Dickson foi superior quando utilizado o esterco de ovino, sendo uma importante

Tabela 4: Valores médios das variáveis respostas das mudas de aroeira-do-sertão (Myracrodruon urundeuva) em função de diferentes substratos e percentagens na mistura com solo mineral

\begin{tabular}{lccccccccc}
\hline Adubos & Al $(\mathbf{c m})$ & $\mathbf{C R}(\mathbf{c m})$ & $\mathbf{D C}(\mathbf{m m})$ & Clor. A & Clor. B & IQD & MSR & MST & AF \\
\hline Esterco bovino & $27,69 \mathrm{~b}$ & $23,15 \mathrm{~b}$ & $2,73 \mathrm{~b}$ & $26,58 \mathrm{~b}$ & $4,64 \mathrm{~b}$ & $0,21 \mathrm{~b}$ & $0,86 \mathrm{~b}$ & $2,73 \mathrm{~b}$ & $302,01 \mathrm{~b}$ \\
Esterco ovino & $39,17 \mathrm{a}$ & $31,70 \mathrm{a}$ & $3,79 \mathrm{a}$ & $29,65 \mathrm{a}$ & $5,48 \mathrm{a}$ & $0,38 \mathrm{a}$ & $1,38 \mathrm{a}$ & $1,38 \mathrm{a}$ & $546,65 \mathrm{a}$ \\
Húmus de minhoca & $35,10 \mathrm{a}$ & $28,07 \mathrm{ab}$ & $3,34 \mathrm{ab}$ & $28,99 \mathrm{a}$ & $5,47 \mathrm{a}$ & $0,24 \mathrm{~b}$ & $0,82 \mathrm{~b}$ & $0,82 \mathrm{~b}$ & $457,12 \mathrm{ab}$ \\
Resíduo do café & - & - & - & - & - & - & - & - & - \\
\hline
\end{tabular}

Médias seguidas pelas mesmas letras nas colunas são iguais entre si pelo teste de Tukey, $\mathrm{p}<0,05$. Altura de plantas (Al, cm), comprimento da raiz $(\mathrm{CR}, \mathrm{cm})$, diâmetro do caule (DC, mm), teores de clorofila $a$ e $b$ e índice de qualidade de Dickson (IQD), massa seca da raiz (MSR, $\mathrm{g})$, massa seca total (MST, g) e área foliar $\left(\mathrm{AF} \mathrm{cm}^{2}\right)$.

Tabela 5: Massa seca da parte aérea de aroeira-do-sertão (Myracrodruon urundeuva) em função de diferentes substratos e percentagens na mistura com solo mineral

\begin{tabular}{|c|c|c|c|c|}
\hline \multirow{3}{*}{ Adubo } & \multicolumn{4}{|c|}{ Massa seca da parte aérea } \\
\hline & \multicolumn{4}{|c|}{ Percentagem } \\
\hline & 33,33 & 50,00 & 66,66 & 75,00 \\
\hline Bovino & $1,95 \mathrm{~b}$ & $1,47 \mathrm{a}$ & $3,29 \mathrm{ab}$ & $0,75 \mathrm{~b}$ \\
\hline Ovino & $4,31 \mathrm{a}$ & $2,06 \mathrm{a}$ & $5,03 \mathrm{a}$ & $3,55 \mathrm{a}$ \\
\hline Húmus & $3,21 \mathrm{ab}$ & $2,60 \mathrm{a}$ & $1,96 \mathrm{~b}$ & $2,74 \mathrm{ab}$ \\
\hline Resíduo do café & - & - & - & - \\
\hline
\end{tabular}

Médias seguidas pelas mesmas letras nas colunas são iguais entre si pelo teste de Tukey, $\mathrm{p}<0,05$.

Rev. Ceres, Viçosa, v. 64, n.1, p. 001-011, jan/fev, 2017 
variável a ser considerada quando se busca produzir mudas de qualidade, pois leva em consideração uma série de variáveis importantes. Gomes \& Paiva (2004) salientaram que o IQD deve ter o valor mínimo de 0,20. Com exceção do resíduo do café, todos os adubos aqui utilizados se adequaram a esse padrão. Entretanto, esses autores fizeram essa análise com base na qualidade de mudas das espécies Pseudotsuga menziessi e Picea abies, podendo, talvez, não ser o mais indicado para a espécie deste estudo. As informações sobre IQD ainda são escassas na literatura, especialmente a respeito dos valores que as mudas de determinada espécie devem atingir para estarem aptas a serem expedidas do viveiro (Tsukamoto Filho et al., 2013).

Queiroz et al. (2012) determinaram IQD de 0,11 para Schizolobium amazonicum; Binotto (2007) obteve 0,05 para Eucalyptus grandis e 0,16 para Pinus elliotii, e Fonseca et al. (2002) estabeleceram 0,20 para Trema micrantha, embora os autores não tenham afirmado que esses valores sejam aqueles ideais para as espécies.

O esterco de ovino proporcionou maior incremento das massas secas total e de raiz (Tabela 4), sendo essas variáveis utilizadas na determinação do IQD, estando, desse modo, diretamente associadas com a eficiência superior observada para o esterco de ovino no cálculo do índice. Esse comportamento sugere que mudas de aroeira produzidas com esterco de ovino na formulação do substrato terão maiores chances de sobrevivência, quando levadas a campo.

Contudo, conforme Silva et al. (2002), é difícil garantir estabilidade nutricional com o esterco de ovino, podendo, assim, ocorrer alteração na resposta da espécie, em razão da aplicação do resíduo. A referida alteração decorre do fato de os teores de nutrientes apresentarem ampla variação nos lotes das diferentes regiões, sendo dependentes de uma série de fatores.

A área foliar pode ser considerada uma das mais importantes variáveis para obtenção de sucesso na produção florestal, tendo em vista que está diretamente associada à taxa fotossintética. Teoricamente, plantas que apresentam maior área foliar produzem maior quantidade de fotoassimilados. Para essa variável, não ocorreu variação estatística entre os efeitos do esterco de ovino e do húmus de minhoca, apresentando ambos comportamento semelhante aos observados na maioria das variáveis presentes na Tabela 1. Possivelmente, em função das respostas observadas, o húmus e o esterco de ovino apresentam concentrações ideais de nutrientes.

A massa seca da parte aérea também se configura como componente do cálculo do IQD, sendo considerada importante característica associada à qualidade de mudas. Neste trabalho, foi constatada variação entre o húmus e o esterco de ovino apenas na percentagem de $66 \%$; no en- tanto, para essa concentração o esterco de bovino não diferiu estatisticamente do esterco de ovino. Para as demais concentrações, o esterco de bovino apresentou resultados inferiores aos do esterco de ovino (Tabela 5).

O esterco de ovino, apesar de apresentar menor concentração mineral (Tabela 2) que o de bovino, proporcionou maiores incrementos, de forma geral, das variáveis analisadas, atribuídos aos níveis ideais encontrados nesse esterco e ao equilíbrio entre as propriedades químicas do substrato. A percentagem de $50 \%$ foi a única em que não foi observada variação significativa para as três formas de adubação.

Quando avaliados em função das percentagens de resíduo, por, regressão, o tratamento com esterco de bovino apresentou padrãolinear, mostrando que, à medida que era elevada a concentração desse adubo, a planta respondia de forma negativa para altura, diâmetro do coleto e comprimento da raiz, com 20,35; 1,95; 12,99 respectivamente, confirmando assim a ação tóxica provocada pelo excesso de nutrientes. O húmus de minhoca não apresentou variação para nenhuma das variáveis analisadas, não respondendo ao incremento de adubo (Figura 2).

A aroeira-do-sertão apresentou comportamento cúbico quando adubada com esterco de ovino, com melhor resposta para a percentagem de $66 \%$, com exceção do comprimento da raiz, com máxima eficiência na dose $33 \%$, com $35,5 \mathrm{~cm}$ (Figura 2). Essa baixa resposta ao uso de $50 \%$ de esterco de ovino na formulação pode estar associada à baixa presença de nutrientes. Quando mais elevado (66\%), proporcionou maior benefício, chegando ao ponto de toxidez, como pode ser observada nas doses de $75 \%$ do resíduo. Em estudo com a aplicação de diversos estercos, Brito et al. (2005) concluíram que o esterco de ovino foi o resíduo que determinou as principais alterações das propriedades químicas do solo, uma vez que, em relação à testemunha, promoveu os maiores aumentos de cálcio, matéria orgânica e capacidade de troca de cátions. A velocidade de decomposição e a consequente mineralização dos resíduos orgânicos interferem diretamente na disponibilidade de nutrientes para as plantas.

Substratos com esterco de bovino proporcionaram ajuste cúbico com máxima eficiência na percentagem de $64,30 \%$ de esterco bovino, obtendo-se 3,0 g de massa seca da parte aérea. As variáveis massa seca da raiz e índice de qualidade de Dickson apresentaram comportamento semelhante (Figura 3).

O húmus de minhoca proporcionou variação apenas para os teores de clorofilas A e B, sendo ele quadrático, com máxima eficiência na percentagem de $33 \%$ de húmus na formulação do substrato, com médias de 29,98 e 6,19 para clorofilas A e B respectivamente (Figura 3). Para o esterco de ovino, foi observado comportamento cúbico das mudas de aroeira para as massas secas da parte aérea 

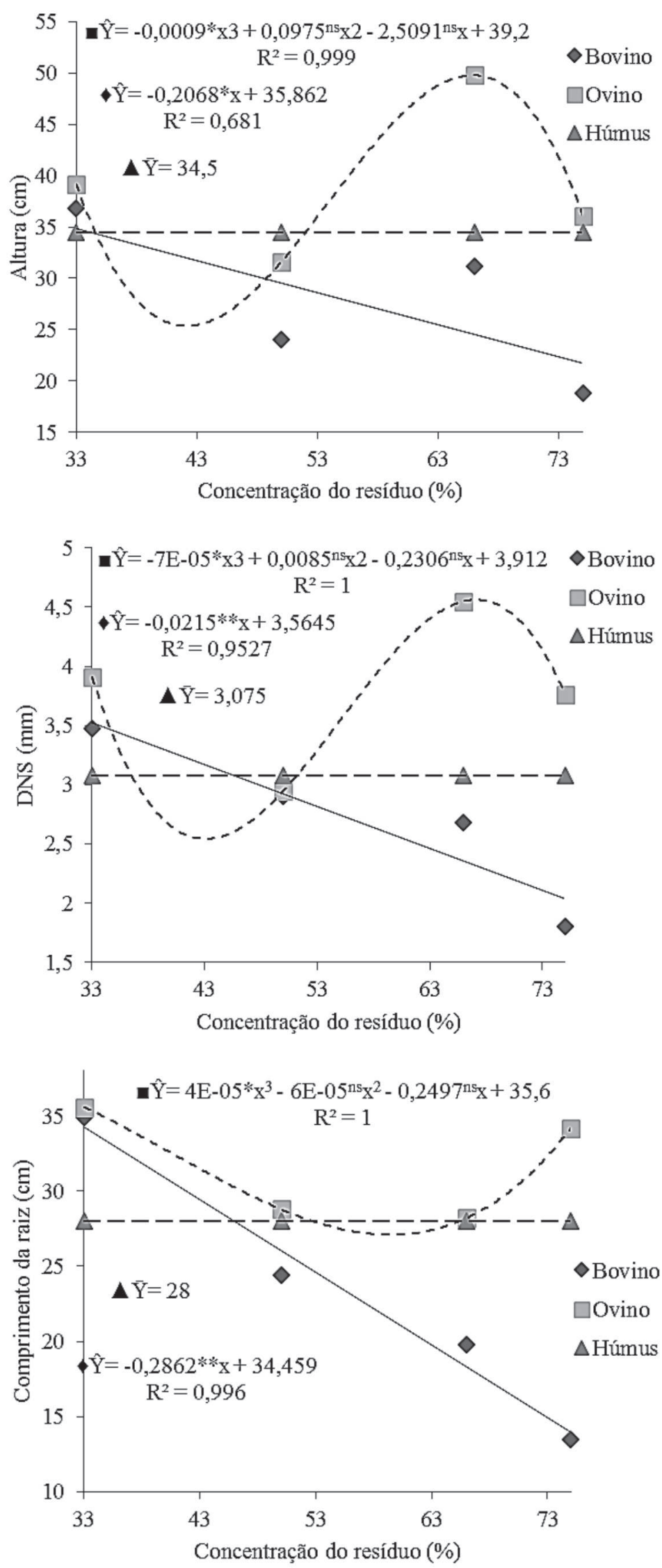

Figura 2: Altura, diâmetro do caule e comprimento da aroeira-do-sertão (Myracrodruon urundeuva) em função de diferentes substratos e percentagens na mistura com solo mineral

$\mathrm{ns}, * *$ e *: não significativo e significativo a 1 e $5 \%$, respectivamente, pelo teste de $\mathrm{F}$.

Rev. Ceres, Viçosa, v. 64, n.1, p. 001-011, jan/fev, 2017 
e da raiz e índice de qualidade de Dickson. A massa seca da parte aérea obteve maior incremento na proporção de $67,30 \%$ com $5,97 \mathrm{~g}, \log$ a após, foi observado efeito tóxico com redução da massa seca.

A composição química dos estercos é variável, influenciada por vários fatores, como a espécie animal, a raça, a idade, a alimentação, o material utilizado como cama, o índice de aproveitamento de nutrientes da ração pelos animais, os produtos veterinários fornecidos, além de outros. Estercos oriundos de produções animais em pasto apresentam mais fibras e são menos ricos em nutrientes. Em relação aos animais adultos, os
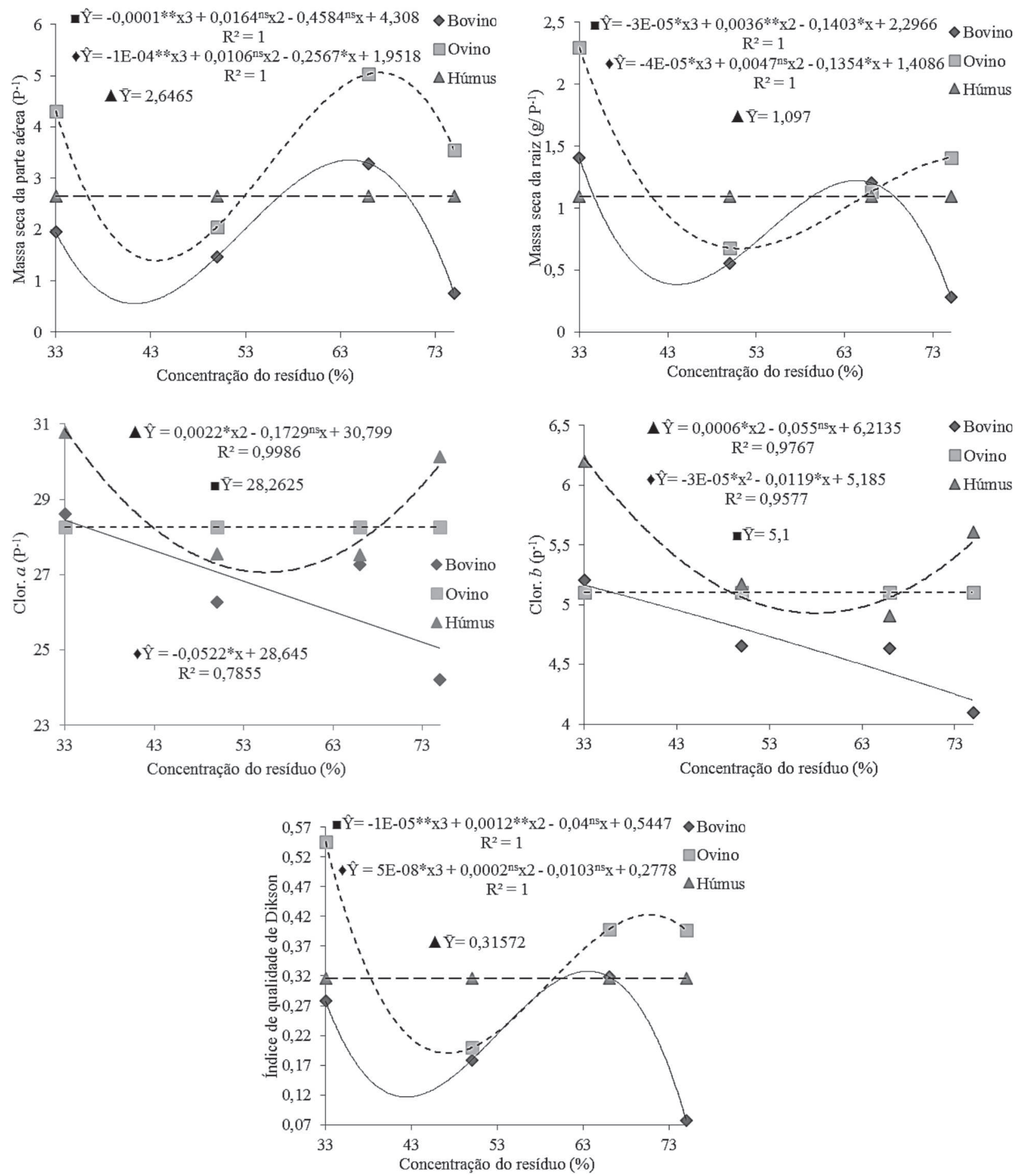

Figura 3: Massas secas de parte aérea e raiz, clorofilas A e B e índice de qualidade de Dickson de mudas de aroeira-do-sertão (Myracrodruon urundeuva) em função de diferentes substratos e percentagens na mistura com solo mineral $\mathrm{ns}, * *$ e *: não significativo e significativo a 1 e $5 \%$, respectivamente, pelo teste de $\mathrm{F}$. 
jovens aproveitam melhor o alimento fornecido e isto implica estercos com menor reserva de nutrientes (Tedesco, 2008).

O substrato formulado a partir do esterco bovino ocasionou diminuição da maioria das variáveis em função do acréscimo de esterco. A matéria orgânica em grandes concentrações pode provocar efeito contrário na planta, inibindo a síntese de substâncias e seu desenvolvimento. O aumento na concentração de esterco possivelmente promoveu bloqueio dos sítios de adsorção de P no substrato, pela ligação dos grupos funcionais carboxílicos e fenólicos da $\mathrm{MO}$ às hidroxilas dos óxidos de $\mathrm{Fe}$ e $\mathrm{Al}$ e complexação do Al em solução (HUE, 1991). Sampaio et al. (2007) constataram que o esterco bovino causou imobilização de nutrientes do solo no primeiro mês após sua incorporação; depois desse período, a liberação aumentou progressivamente, atingindo as maiores quantidades entre três e seis meses após a incorporação.

\section{CONCLUSÕES}

O esterco ovino e o húmus de minhoca são os resíduos orgânicos mais recomendados para a produção de mudas de aroeira sob as condições testadas, nas concentrações de 66 e $33 \%$ respectivamente.

O resíduo do café não deve ser usado nessas concentrações na produção de mudas de aroeira, em função do seu efeito alelopático.

O esterco bovino proporcionou resultados intermediários aos dos outros resíduos, no desenvolvimento das mudas de aroeira, com maior eficiência na concentração de $33 \%$.

\section{AGRADECIMENTOS}

Os autores agradecem ao grupo Três Corações pela disponibilização do resíduo de café utilizado no experimento.

Agradecem também à Coordenação de Aperfeiçoamento de Pessoal de Nível Superior (CAPES), pela bolsa de Mestrado do Primeiro autor.

\section{REFERÊNCIAS}

Araújo AP de \& Sobrinho S de P (2011) Germinação e produção de mudas de tamboril Enterolobium contortisiliquum (vell.) morong) em diferentes substratos. Revista Árvore, 35:581-588.

Bertoni JE de A \& Dickfeldt EP (2007) Plantio de Myracrodruon urundeuva fr. all. (aroeira) em área alterada de floresta: desenvolvimento das mudas e restauração florestal. Revista do Instituto Florestal, 19:31-38.

Binotto AF (2007) Relação entre as variáveis de crescimento e o índice de qualidade de Dickson em mudas de Eucalyptus grandis W. Hill ex Maid e Pinus elliottii var. elliottii - Engelm. Dissertação de Mestrado. Universidade Federal de Santa Maria, Santa Maria. 56p.
Brito OR, Vendrame PRS \& Brito RM (2005) Alterações das propriedades químicas de um Latossolo Vermelho distroférrico submetido a tratamentos com resíduos orgânicos. Semina: Ciências Agrárias, 26:33-40.

Caldeira MV, Gomes DR, Gonçalves E de O, Delarmelina WM, Sperandio HV \& Trazzi PA (2012) Biossólido como substrato para produção de mudas de Toona ciliata var. australis. Revista Árvore, 36:1009-1017.

Caldeira MVW, Rosa GN da, Fenilli TAB \& Harbs RMP (2008) Composto orgânico na produção de mudas de aroeira-vermelha. Scientia Agraria, 9:27-33.

Cruz CAF, Paiva HN \& Guerrero CRA (2006) Efeito da adubação nitrogenada na produção de mudas de sete-cascas (Samanea inopinata (Harms) Ducke). Revista Árvore, 30:537-546.

Cunha AO, Andrade LA, Bruno RLA, Silva JAL \& Souza VC (2005) Efeitos de substratos e das dimensões dos recipientes na qualidade das mudas de Tabebuia impetiginosa (Mart. Ex D.C.) Standl. Revista Árvore, 29:507-516.

Dickson A, Leaf AL \& Hosner JF (1960) Quality appraisal of white spruce and white pine seedling stock in nurseries. Forestry Chronicle, 36:11-13.

Faustino R, Kato MT, Florêncio L \& Gavazza S (2005) Lodo de esgoto como substrato para a produção de mudas de Senna siamea Lam. Revista Brasileira de Engenharia Agrícola e Ambiental, 9:278-282.

Fonseca EP, Valeri SV, Miglioranzi E, Fonseca NAN \& Couto L (2002) Padrão de qualidade de mudas de Trema microntha (L.) Blume, produzidas sob diferentes períodos de sombreamento. Revista Árvore, 26:515-523.

Gomes JM \& Paiva HN (2004) Viveiros florestais (propagação sexuada). Viçosa, Universidade Federal de Viçosa. 116p.

Hue NV (1991) Effects of organic acids/anions on P sorption and phytoavailability in soils with different mineralogies. Soil Science and Plant Analysis, 152:463-471.

José AC, Davide AC \& Oliveira SL de (2005) Produção de mudas de aroeira (Schinus terebinthifolius raddi) para recuperação de áreas degradadas pela mineração de bauxita. Cerne, 11:187196.

Kratka PC \& Correia CRM de A (2015) Crescimento inicial de aroeira-do-sertão (Myracrodruon urundeuva allemão) em diferentes substratos. Revista Árvore, 39:551-559.

Kratz D, Wendling I, Nogueira AC \& Souza PVde (2013) Propriedades físicas e químicas de substratos renováveis. Revista Árvore, 37:1103-1113.

Lima JD, Moraes W da S, Mendonça JC de \& Nomura ES (2007) Resíduos da agroindústria de chá preto como substrato para produção de mudas de hortaliças. Ciência Rural, 37:1609-1613.

Lorenzi H (2010) Árvores brasileiras: manual de identificação e cultivo de plantas arbóreas nativas do Brasil. $5^{\text {a }}$ ed. Nova Odessa, Instituto Plantarum. 384p.

Monteiro JM, Lins Neto EM de F, Amorim ELC de, Strattmann RR, Araújo EL \& Albuquerque UP de (2005) Teor de taninos em três espécies medicinais arbóreas simpátricas da caatinga. Revista Árvore, 29:999-1005.

Morais WCM, Susin F, Vivian MA \& Araújo MMM (2012) Influência da irrigação no crescimento de mudas de Schinus terebinthfolius. Pesquisa Forestal Brasileira, 32:23-28.

Oliveira J da S, Nunes HB, Soares Neto JP \& Reis TC (2012) Desenvolvimento inicial da aroeira (Myracrodruon urundeuva) com uso de substratos agroindustriais. Revista de Biologia e Ciências da Terra, 12:09-13. 
Pacheco MV, Matos VP, Ferreira RLC, Lícia A, Feliciano P \& Silva KM (2006) Efeito de temperaturas e substratos na germinação de sementes de Myracrodruon urundeuva Fr. All. (ANACARDIACEAE). Revista Árvore, 30:359-67.

Pelissari RAZ, Sampaio SC, Gomes SD \& Crepalli M da S (2009) Lodo têxtil e água residuária da suinocultura na produção de mudas de Eucalyptus grandis (W. Hill ex Maiden). Engenharia Agrícola, 29:288-300.

Pelizer LH, Pontieri MH \& Moraes IO (2007) Utilização de resíduos agro-industriais em processos biotecnológicos como perspectiva de redução do impacto ambiental. Journal of Technology Management and Innovation, 2:118-127.

Queiroz FLC, Scaramuzza WLMP \& Tsukamoto AAF (2012) Influência do lodo de caleiro na qualidade de mudas de pinhocuiabano. Multitemas, 42:101-113.

Rosa SDVF, Santos CG dos, Paiva R, Melo PLQ de, Veiga AD \& Veiga AD (2006) Inibição do desenvolvimento in vitro de embriões de coffea por cafeína exógena. Revista Brasileira de Sementes, 28:177-184.

Sampaio EV de SB, Oliveira NMB de \& Nascimento PRF do (2007) Eficiência da adubação orgânica com esterco bovino e com Egeria densa. Revista Brasileira de Ciência do Solo, 31:9951002 .
Scalon S de PQ, Scalon Filho H \& Masetto TE (2012) Aspectos da germinação e desenvolvimento inicial de plântulas de aroeira. Cerne, 18:533-539.

Silva LMM, Rodrigues TJD \& Aguiar IB (2002) Efeito da luz e da temperatura na germinação de sementes de aroeira (Myracrodruon urundeuva Allemão). Revista Árvore, 26:691697.

Souza CAM de, Oliveira RB de, Martins Filho S \& Lima JS de S (2006) Desenvolvimento em campo de espécies florestais em diferentes condições de adubação. Ciência Florestal, 16:243249.

Taiz L \& Zeiger E (2013) Fisiologia Vegetal. 5 ${ }^{\text {a }}$ ed. Porto Alegre, Artmed. 848p.

Tedesco MJ (2008) Resíduos orgânicos no solo e os impactos no ambiente. In: Santos GA, Silva LS, Canellas LP \& Camargo FAO (Eds.) Fundamentos da matéria orgânica do solo: ecossistemas tropicais e subtropicais. $2^{\mathrm{a}}$ ed. Porto Alegre, Metrópole. p.113-136.

Tsukamoto Filho A de A, Carvalho JLO, Costa RB da, Dalmolin ÂC \& Brondani GE (2013) Regime de Regas e Cobertura de Substrato Afetam o Crescimento Inicial de Mudas de Myracrodruon urundeuva. Floresta e Ambiente, 20:521-529. 